\title{
Biocatalytic Alkylation Cascades: Recent Advances and Future Opportunities for Late-Stage Functionalization
}

\author{
Iain J.W. McKean, ${ }^{[a]}$ Paul A. Hoskisson, ${ }^{*[b]}$ and Glenn A. Burley*[a]
}

\author{
[a] Dr I.J.W. McKean \& Prof. G.A. Burley \\ Department of Pure \& Applied Chemistry \\ University of Strathclyde \\ 295 Cathedral Street, Glasgow, United Kingdom, G1 1XL \\ E-mail: glenn.burley@strath.ac.uk \\ [b] Prof. P.A. Hoskisson \\ Strathclyde Institute of Pharmacy \& Biomedical Sciences \\ University of Strathclyde \\ 161 Cathedral Street, Glasgow, United Kingdom, G4 ORE \\ E-mail: paul.hoskisson@strath.ac.uk
}

This diversity provides an excellent foundation to exploit these enzymes for biocatalytic applications. For over a decade, intensive efforts in the biocatalytic arena have focused on understanding the scope and limitations of enzymatic alkylation, with a view to developing the approach into a generalized and sustainable biocatalytic process for late-stage functionalization. ${ }^{[16-}$ 19] In this article, we highlight contemporary new discoveries in the area which potentially take us closer towards establishing a biocatalytic alkylation platform.

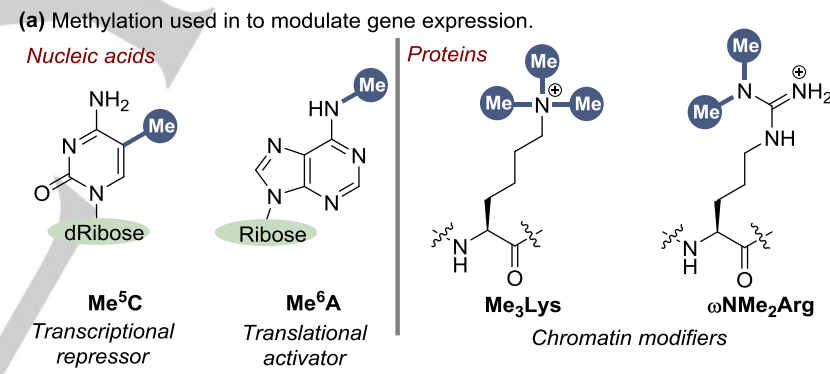

(b) Methylation used to modulate biological activity of small molecules.<smiles>[CH2+]c1c(OC2OC(C)(C)[C@@H](OC)[C@@H](OC(N)=O)[C@@H]2O)ccc2c(O)c(NC(=O)c3ccc(O)c(CC=C(C)C)c3)c(=O)oc12</smiles>

Novobiocin<smiles>COc1ccc(C(=O)NC2CC2)cc1-c1ccc(C(=O)NCC2CC2)cc1</smiles>
Hsp90 inhibitor

$$
\begin{array}{ccc} 
& & \mathrm{IC}_{50}(\mathrm{nM}) \\
1 & \mathrm{H} & >16000 \\
2 & \mathrm{Me} & 75
\end{array}
$$$$
\text { p38 } \alpha \text { MAPK inhibitor }
$$

(c) Enzymatic process of methylation. molecules $^{[13]}$ has spurred the development of new synthetic methodologies to install Me groups at a late-stage in a synthetic workflow with variable levels of chemo/regioselectivity. ${ }^{[14-15]}$ In contrast to chemical approaches, enzymatic methylation, catalyzed by methyltransferases (MTases), is highly chemo/regioselective and involves transfer of a Me group from the S-adenosyl methionine (SAM) cofactor to a target substrate (Figure 1c). A variety of MTases exist in nature, ranging from examples which methylate biomacromolecules such as nucleic acids and proteins, through to examples which are specific for small molecule substrates.

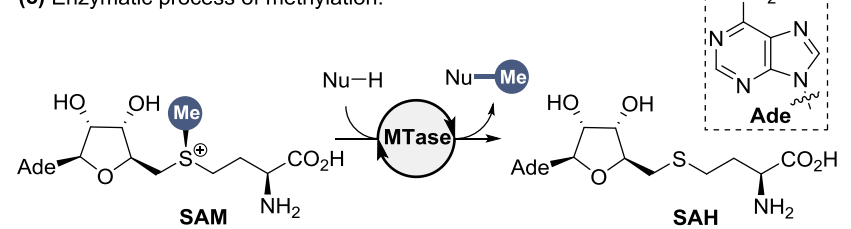

Figure 1. Representative examples of methylated (a) biomacromolecules, and (b) small molecules. (c) Overview of enzymatic methylation. dRibose = 2'deoxyribose, $\mathrm{Nu}=$ nucleophile (e.g., $\mathrm{C}-, \mathrm{S}-, \mathrm{N}-, \mathrm{O}-$ ), $\mathrm{Ade}=$ adeninyl. 


\section{Current Challenges of Biocatalytic Alkylation}

Two major challenges exist in the development of robust and efficient biocatalytic alkylation platforms. The first challenge relates to the synthesis and stability of the SAM cofactor. Although SAM performs the role of nature's 'methyl iodide' protagonist rather effectively, this cofactor is inherently unstable under physiological conditions (e.g., $t_{1 / 2} \sim 942 \mathrm{~min}, \mathrm{pH}$ 8). The degradation of SAM arises from a combination of intramolecular cyclization to form 5 '-deoxy-5'-(methylthio)adenosine (3) and Lhomoserine lactone (4), and depurination to form adenine (5) and S-ribosylmethionine (6, Figure 2a). ${ }^{[20]}$ Efforts to circumvent the need to prepare SAM analogues separately have focused on developing tandem enzymatic reactions, where the cofactor is synthesized in situ, followed by MTase-mediated methylation. ${ }^{21-}$ ${ }^{27]}$ Another alternative is to develop shelf-stable SAM analogues (e.g., 7-9), which are accepted by MTases as substrates but could also be stored prior to use (Figure 2b). ${ }^{20]}$

The second challenge in establishing a biocatalytic methylation platform arises from the inherent need to use stoichiometric amounts of the SAM cofactor (or analogue), which invariably produces an equal amount of the by-product $S$ adenosylhomocysteine (SAH). ${ }^{[28-29]}$ Since a buildup of $\mathrm{SAH}$ is inhibitory to a variety of MTases, the development of methods which can minimize the buildup of SAH is essential. ${ }^{[28-29]}$ In contrast to other small molecule cofactors such as $\mathrm{NAD}^{+} / \mathrm{NADH}$, which involve a single regeneration step, ${ }^{[30]}$ the metabolic breakdown of SAH in nature is a multi-step process (Figure 3a). ${ }^{[31]}$ Therefore, the development of an efficient SAM regeneration system which does not cause the concentration of SAH to reach levels which inhibit MTase activity is essential to establish a generalized enzymatic biocatalytic alkylation platform. ${ }^{[18]}$

\section{Development of SAM Cofactor Regeneration Systems}

Andexer and co-workers recently reported the first SAM cofactor regeneration strategy, which integrates an MTase-mediated (a) Degradation pathways of SAM

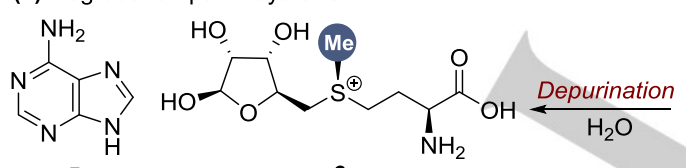

5 adenine

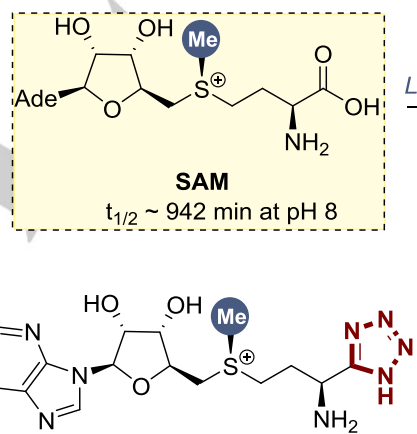

8

$\mathrm{t}_{1 / 2} 5007 \mathrm{~min}$ at $\mathrm{pH} 8$

Depurination degradation pathway

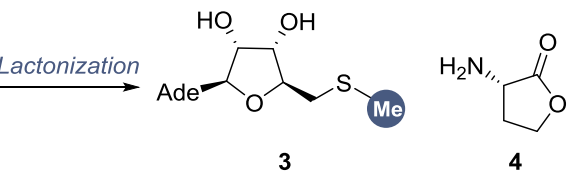

5'-deoxy-5'(methylthio)adenosine L-homoserine lactone<smiles>Nc1ncnc2c1ccn2C1OC(C[As]([18OH])CC[C@H](N)C(=O)O)[C@H](O)[C@H]1O</smiles>

7

$\mathrm{t}_{1 / 2} 1243 \mathrm{~min}$ at $\mathrm{pH} 8$

Lactonization degradation pathway (m)ethylation with a multi-step phosphorylation process to form ATP. ${ }^{[32] ~ A f t e r ~(m) e t h y l ~ t r a n s f e r, ~ S A H H ~ d e g r a d e s ~ S A H ~ t o ~ f o r m ~}$ enosine and L-homocysteine. Successive phosphorylation steps of Ado catalyzed by ADK, PPK2-I and PPK2-II forms ATP. The formation of SAM via the coupling of ATP with methionine (Met) is catalyzed by MAT (Figure $3 \mathrm{~b}$ ). A catalytic amount of AMP is used to initiate the reaction cascade and was shown to be compatible with a range of small molecules, using a range of $N$-, $O$ - and C-MTases. Furthermore, the compatibility of the regeneration system was extended to both $\mathrm{Me}$ and ethyl (Et) groups (Et transfer via the in situ formation of S-adenosylethionine, $\mathrm{SAE}$, when methionine is replaced by ethionine) to produce (m)ethylated products such as 10 and 11.

Whilst this work demonstrated a landmark proof of concept of SAM regeneration, the sophistication of the system (six enzymes) and a low rate of turnover (typically 10-11 regeneration cycles) resulted in low yields of (m)ethylated products. One origin of the low yield of $(\mathrm{m})$ ethylated products could arise from the slow turnover rate of $\mathrm{SAHH},{ }^{[33-34]}$ which in turn can result in a build-up toward inhibitory levels of SAH and L-homocysteine. In order to circumvent this issue, a streamlined cofactor regeneration system has recently been described by Liao \& Seebeck (Figure 3c). ${ }^{[35]}$ The first step in the process involves MTase-mediated Me transfer using SAM as the Me source. The innovative step in this work arises from converting SAH directly to SAM using HMT and methyl iodide as the Me source (Figure 3c). This elegant twoenzyme strategy was compatible with $\mathrm{N}$-, $\mathrm{O}$ - and $\mathrm{C}-\mathrm{MT}$ ases and was applied in reactions such as the $C$-methylation of 12 to 13 . A hallmark of this regeneration system is the ability of HMTase and the corresponding MTases to tolerate methyl iodide, which could potentially act as an indiscriminate methylating agent. Surprisingly, this did not pose a major problem in this context as demonstrated by regeneration cycles ranging from 35-290. Although, in its current guise, the enzymatic platform might be limited to in vitro applications with methyl iodide as the methylating agent, there exists distinct opportunities to engineer this platform to use much milder electrophilic agents, which could be compatible with in cell or lysate-based systems. ${ }^{[36]}$

Figure 2. (a) Degradation products formed as a result of SAM degradation. (b) Development of degradation-resistant SAM analogues by Thorson et al. ${ }^{[20]}$ 
(a) Naturally-occurring SAM regeneration cycle.

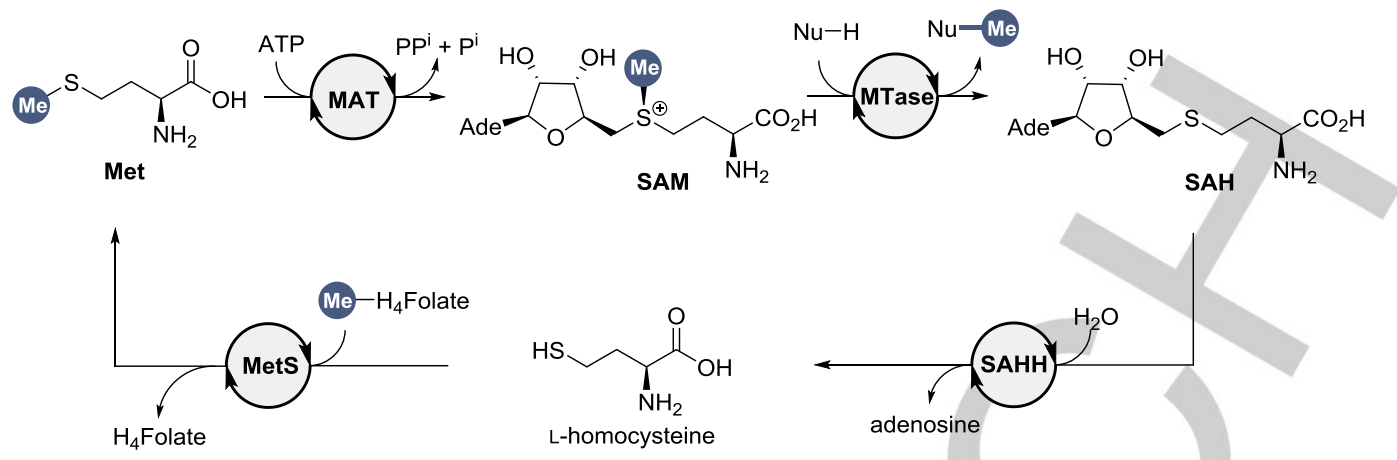

(b) Biocatalytic (m)ethylation using an artificial SAM/SAE regeneration process (Andexer)
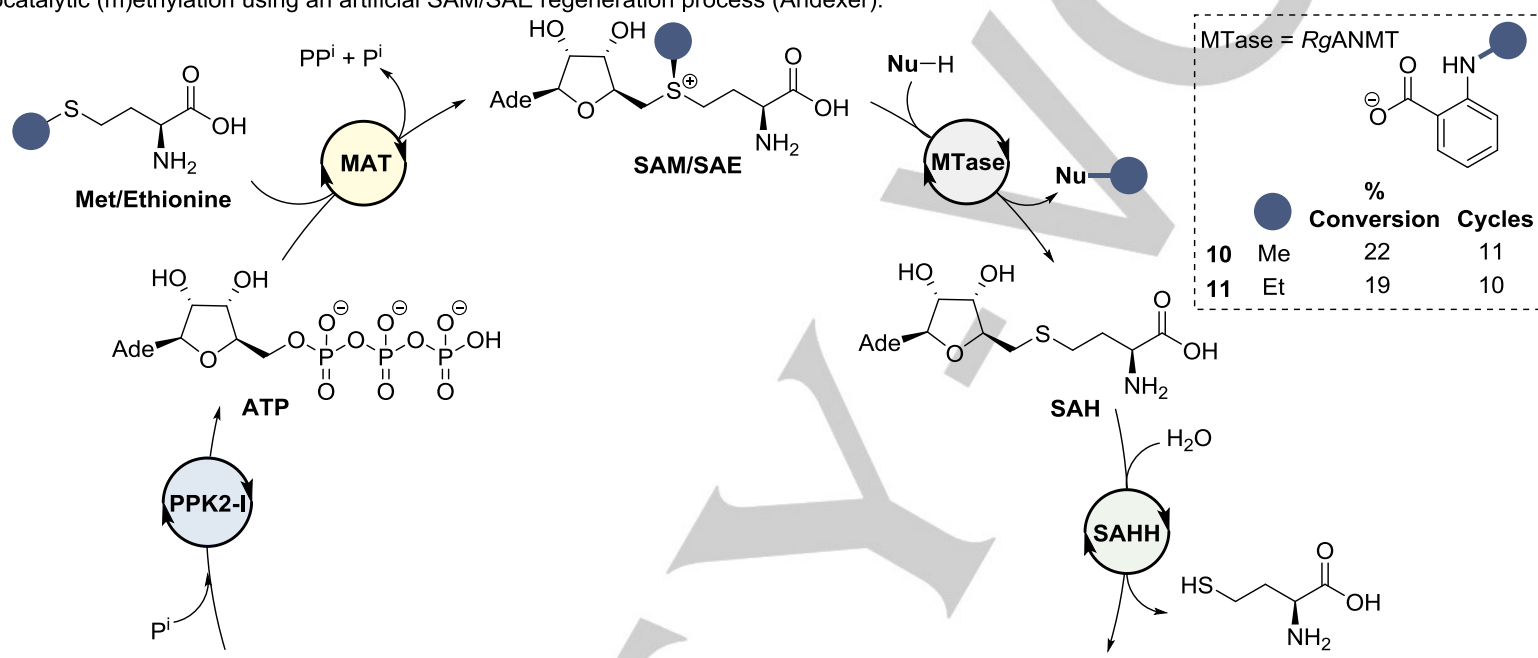

$\%$

Conversion Cycles

$\begin{array}{llll}10 & \mathrm{Me} & 22 & 11 \\ 11 & \mathrm{Et} & 19 & 10\end{array}$
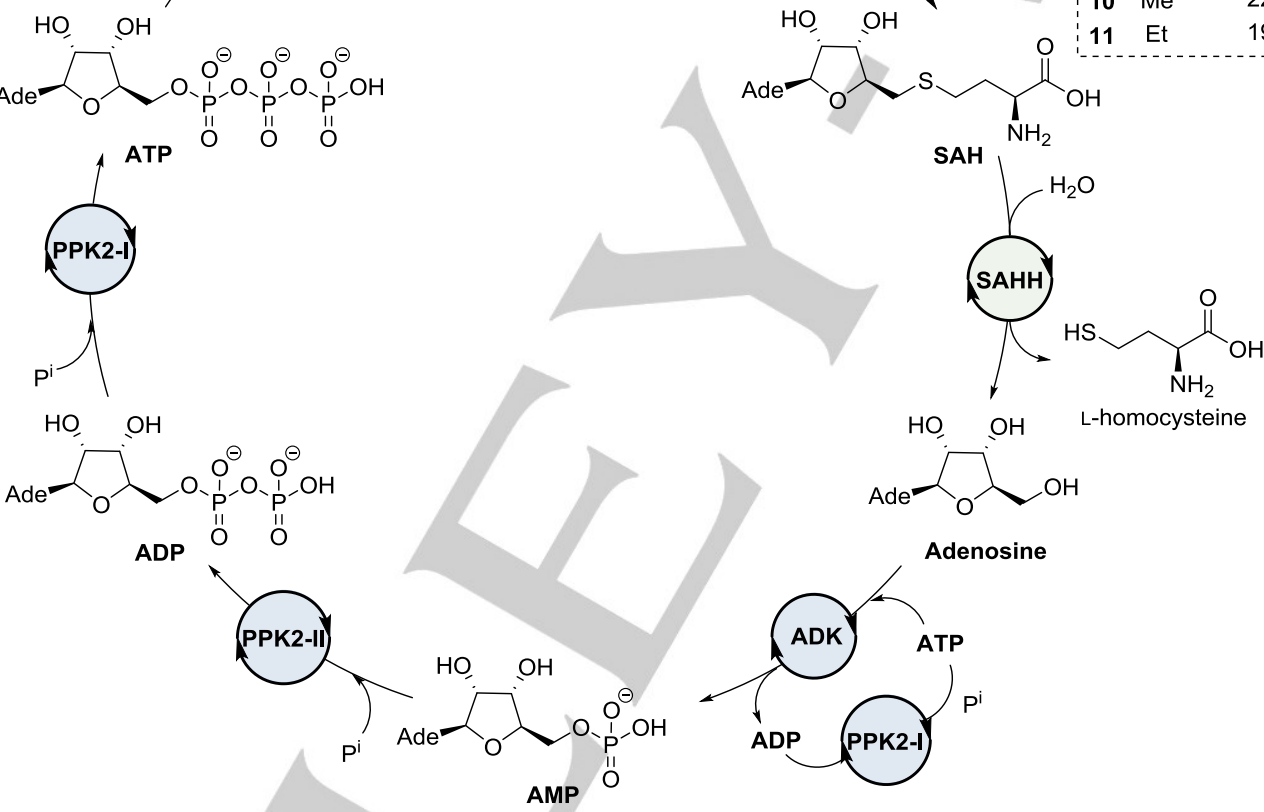

(c) Biocatalytic methylation using a streamlined SAM regeneration process (Seebeck).

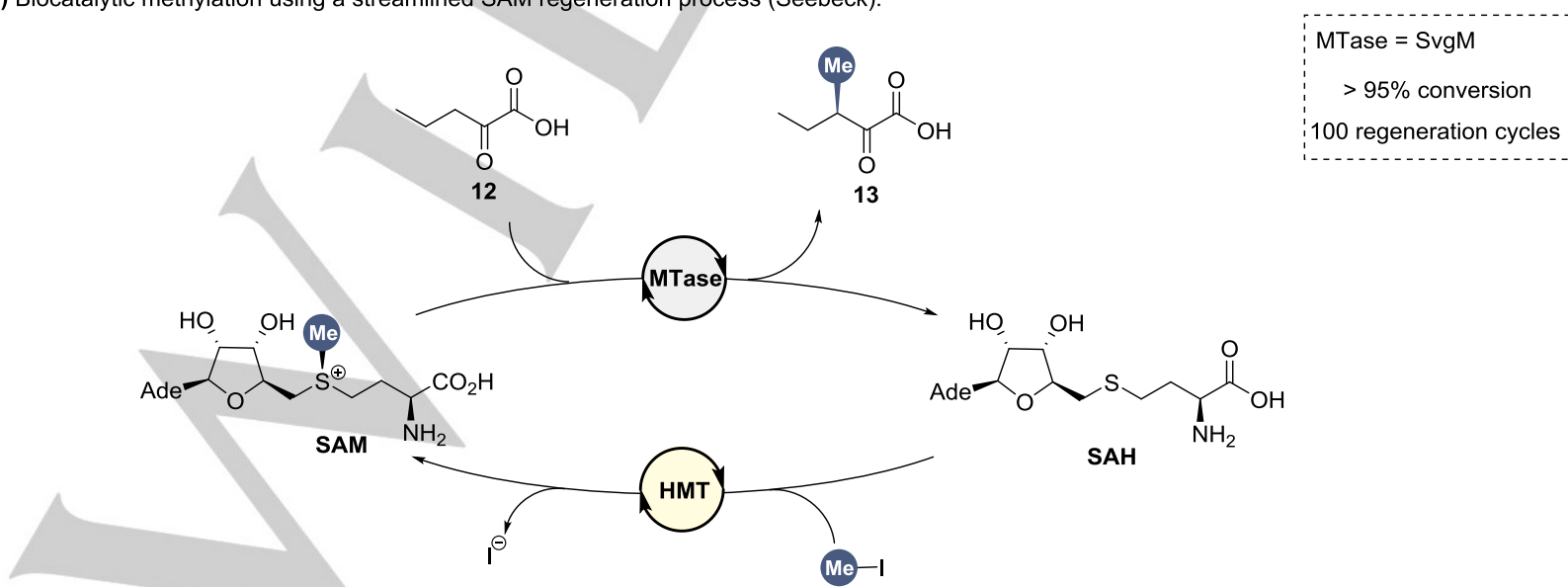

Figure 3. (a) Natural SAM regeneration. ${ }^{[31]}$ Cofactor regeneration pathways using (b) a multi-enzyme process (Andexer), ${ }^{[32]}$ and (b) a streamlined two-enzyme approach (Seebeck). ${ }^{[35]}$ ADK = adenosine kinase; PPK2-I = polyphosphate kinase 2-I; PPK2-I = polyphosphate kinase 2-II; HMT = halide methyltransferase, MAT $=$ methionine adenosyltransferase, $\mathrm{SAHH}=\mathrm{SAH}$ hydrolase, MetS $=$ Met synthase, $\mathrm{H}_{4}$ Folate = tetrahydrofolate. 
(a) Enzymatic alkylation using S/Se-alkylated SAM analogues generated in situ by MAT.

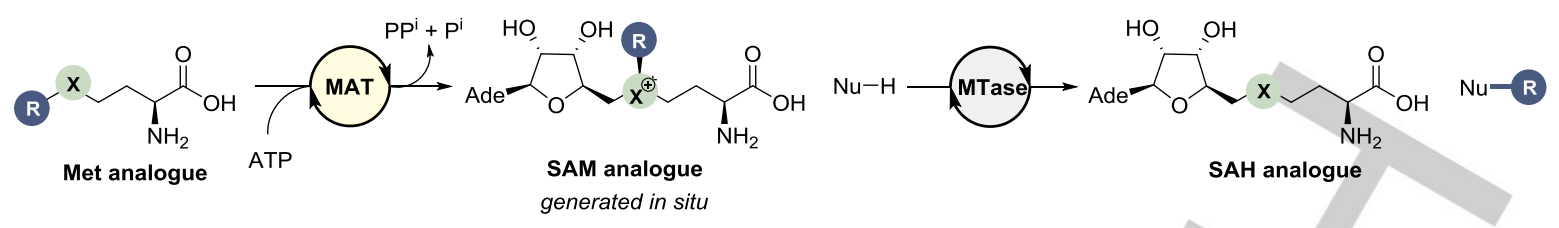

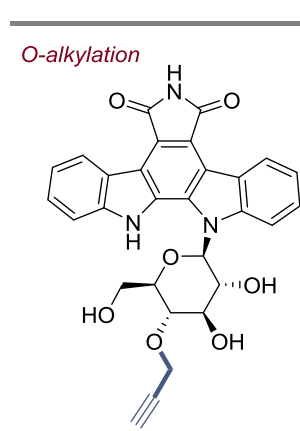

$14 a^{a}(X=S e)$

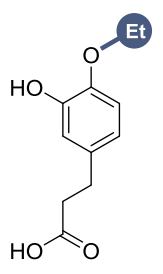

$14 b^{b}(X=S)$

$\mathrm{Nu}-\mathrm{R}$

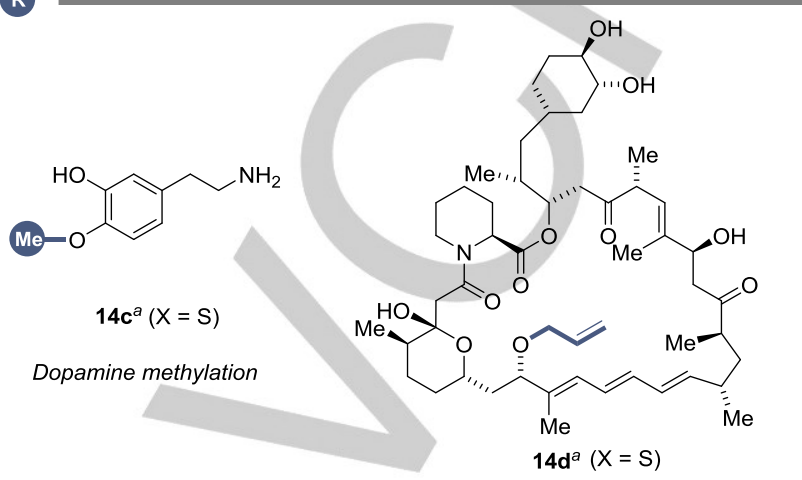

Rebeccamycin alkylation

Catechol alkylation C-alkylation

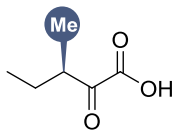

$14 \mathrm{e}^{\mathrm{a}}(\mathrm{X}=\mathrm{S})$

Alkylation of keto acids

(b) $C$-alkylation by HMT SAM regeneration
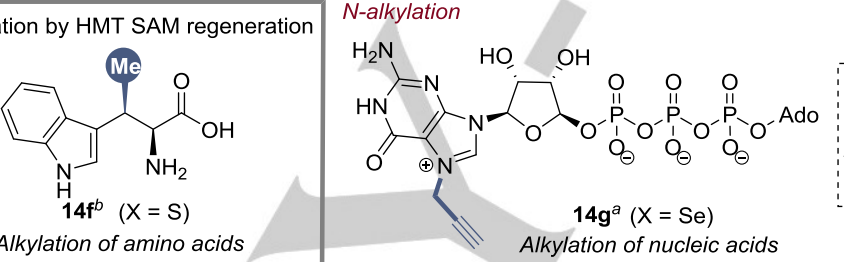

Prerapamycin alkylation

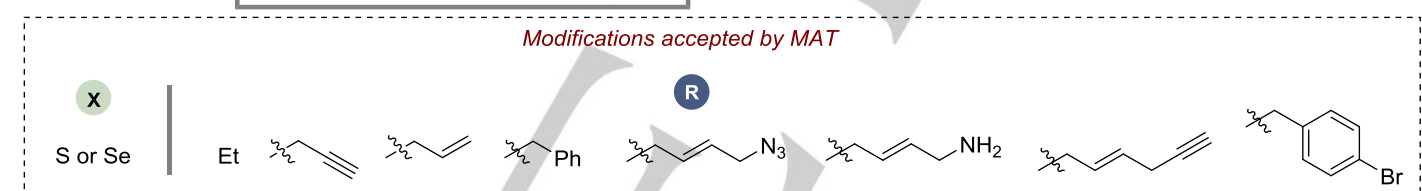

(c) Enzymatic alkylation using $S$ - $(m)$ ethylated SAM analogues generated in situ by SalL.
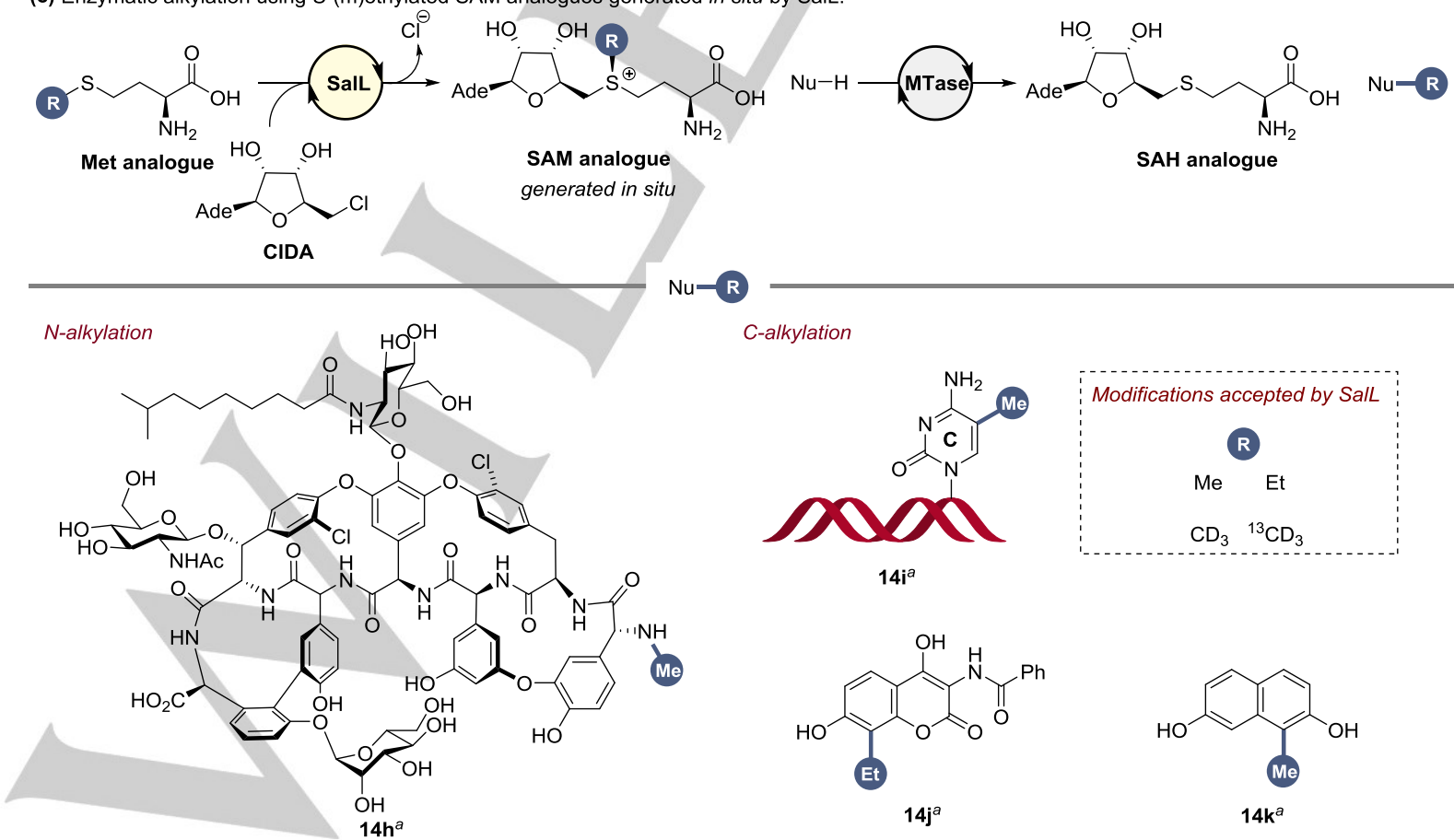

C-alkylation

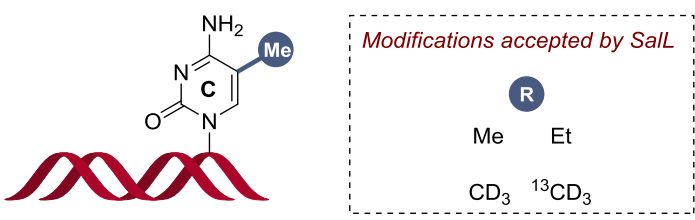

$14 i^{a}$

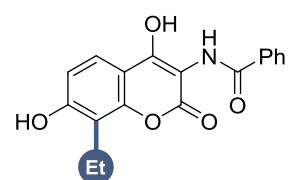

$14 \mathrm{j}^{a}$

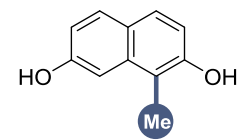

$14 \mathrm{k}^{\mathrm{a}}$

Figure 4. Tandem enzymatic alkylation using (a) MAT, ${ }^{[9,}$ 20-21, 25, 37-39] (b) an HMT-mediated SAM regeneration process, ${ }^{[40]}$ and (c) SalL to generate SAM analogues in situ. ${ }^{a}$ Product prepared using a tandem, linear process. ${ }^{b}$ Product prepared using a cyclic SAM regeneration process. ${ }^{[32,40]}$ 


\section{Enhancing the Scope of Biocatalytic Alkylation using Modified SAM Cofactors}

Both of the pioneering strategies described above showcase the ability to introduce (m)ethyl units into a cofactor regeneration cascade. Whilst this provides a powerful proof of concept demonstration that SAM analogues can be regenerated in a close enzymatic loop, the enzymatic platform could be enhanced even further by diversifying the substrate and/or alkyl group being transferred by MTases. A characteristic of a variety of MTases is the ability of these enzymes to accept alkylated analogues of the SAM cofactor. A pertinent exemplar of this promiscuity is DNA/RNA MTases which accept analogues of SAM and used as a tagging tool for biotechnology-based applications. [19, 25-26, 41-43] Cofactor promiscuity is also a hallmark of a number of small molecule C-MTases such as NovO and CouO, which accepts a variety of S-alkylated SAM analogues prepared separately by chemical synthesis. ${ }^{[4]}$ A distinct limitation of preparing SAM analogues by chemical synthesis is the formation of $R / S$ epimers at the $S$-centre. Since nature only uses the $S$-epimer, ${ }^{[45-46]}$ the efficiency of the process is significantly reduced from a biocatalytic perspective. ${ }^{[16]}$

As a result, enzymatic routes which couple the synthesis of cofactor analogues with alkyl transfer, provide a far more stepand atom-efficient strategy. ${ }^{[20-21]}$ MAT is one SAM-forming enzyme which demonstrates excellent substrate scope for the preparation of $\mathrm{S} / \mathrm{Se}$-alkylated analogues. In nature, MAT uses ATP as the adenosyl donor ${ }^{[44]}$ and methionine to prepare SAM. A solvent accessible active site of MAT enables this enzyme to tolerate analogues of methionine and (seleno)methionine substrates bearing longer alkyl chains and functional handles on $\mathrm{S} / \mathrm{Se}$-centres producing a suite of analogues such as 7-9 (Figure 2). ${ }^{[21,25,39,47-49]}$ The in situ synthesis of these cofactor analogues can then be used as substrates to transfer functional handles catalyzed by a variety of $\mathrm{O}-(\mathbf{1 4 a - d}), C-(\mathbf{1 4 e})$ and $N-(\mathbf{1 4 g})$ MTases (Figure 4a). ${ }^{[9,20-21,25,37-39]}$ In addition, Seebeck et al. expanded their two-enzyme SAM regeneration strategy (Figure $3 \mathrm{~b})^{[35]}$ to stereoselectively prepare $C$-alkylated amino acids such as $\mathbf{1 4 f}$, thereby opening up opportunities to efficiently prepare Lor $D$ - $\beta$-methylated $\alpha$-amino acids, which are challenging to prepare by conventional chemical synthesis (Figure 4b). ${ }^{[40]}$ An atom-efficient alternative to the use of ATP as the adenosyl donor is to use the chlorinase SalL (Salinispora tropica) and 5'chloro-5'-deoxyadenosine (CIDA, Figure 4c). ${ }^{[50]}$ Although the substrate scope of wildtype SalL is narrower than of MAT, $20-21,37$, $39,44,47-48$ SalL is capable of SAM analogue synthesis and is compatible with a range of small molecule $(\mathbf{1 4 h}, \mathbf{j}-\mathbf{k})^{[23-24,27]}$ and DNA (14i) ${ }^{[22,24]}$ MTases, which enhances the flexibility of enzymatic alkylation routes which might not be easily accessible via MAT/HMT-catalyzed strategies (Figure 4a-b).

Our collaboration has focused on increasing the efficiency of tandem enzymatic processes by understanding how strategic modifications to the cofactor influences SAM formation and alkyl transfer. Using SalL to generate cofactor analogues in situ and the small molecule $C$-MTase NovO as the corresponding MTase, we explored the impact of modifying the adenine nucleobase, the ribose sugar and the carboxylic acid ${ }^{[20]}$ of the SAM cofactor on (m)ethyl transfer to coumarin scaffolds. Inspection of the crystal structures of SalL (Figure 5a) $)^{[50]}$ and NovO (Figure 5b) ) $^{[51]}$ identified a complementary cleft in both enzymes where the adenine 2-position is located. We hypothesized that filling the cleft with a modification at this position would enhance the residence time of CIDA (in SalL) and the SAM analogues (in NovO) in the active site of the respective enzymes and could enhance the efficiency of SAM analogue synthesis (SalL) and (me)ethyl transfer (NovO). ${ }^{[52]} \mathrm{A}$ screen of CldA and (m)ethionine analogues identified analogues modified at the adenine 2-position with an exocyclic amine (16a-b) or a chloro (17a-b) group enhanced the efficiency of both SAM analogue formation and (m)ethyl transfer (Figure 6). Interestingly, these 2-modified adenine modifications were also tolerated in the fluorinase enzyme to form 5'-fluoro-5'deoxyadenosine from CIDA. ${ }^{[53-54]}$

The efficiency of (m)ethyl transfer to coumarin substrates in this tandem process (Figure 6) was far higher using cofactors 16-17ab generated in situ relative to naturally occurring SAM. It enabled (m)ethylation of high-value coumarin analogues (18-20) such as the Hsp90 inhibitor (19) and the warfarin metabolite (20). This concept of exploiting modified cofactors generated in situ followed by MTase-mediated alkyl transfer was also recently extended to the MAT enzyme. ${ }^{[25]}$

(a) Active site of SalL in complex with SAM.

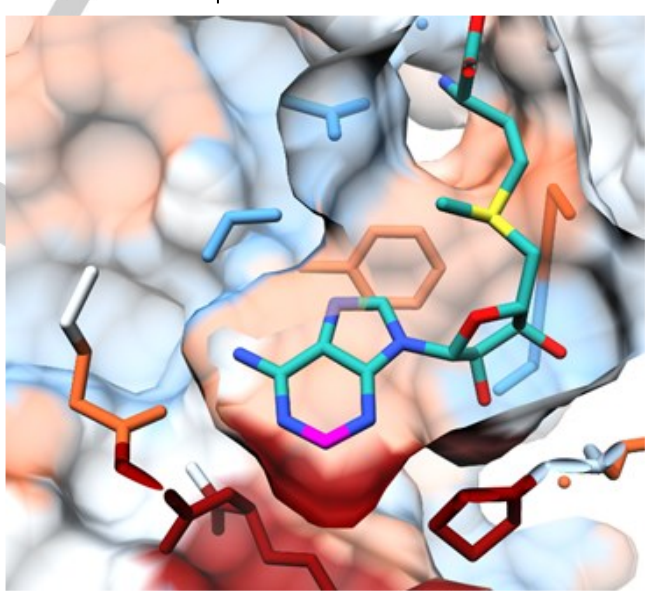

(b) Active site of NovO in complex with SAH.

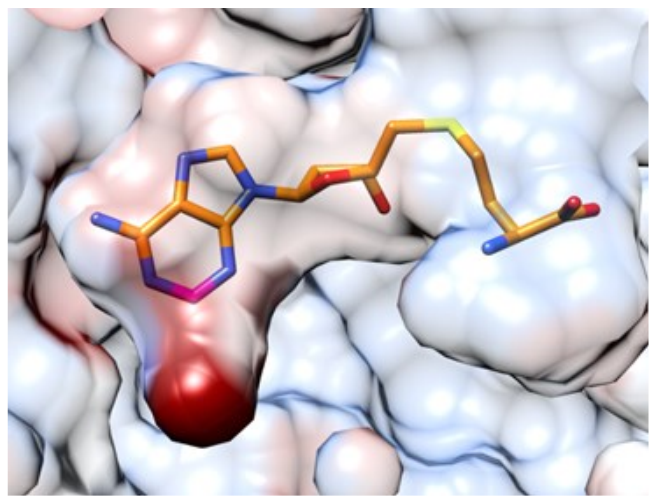

Figure 5. Crystal structures of (a) SalL in complex with SAM (PDB: 6RYZ), and (b) NovO in complex with SAH (PDB: 5MGZ). SAM coloured in cyan, SAH coloured in orange. The N2 position highlighted in pink. The hydrophobic cleft in both enzymes highlighted in red. 
Taken collectively, these works demonstrate the compatibility of coupling SAM analogue formation in situ with MTase-mediated alkyl transfer. ${ }^{[25-27,52]}$ Opportunities to further enhance the efficiency of the process and the substrate scope are now ripe for exploration by, for example, directed evolution techniques, ${ }^{[55-57]}$ which in turn could be integrated into the aforementioned emerging cofactor regeneration strategies (Figure 3b-c). ${ }^{[32,35]}$<smiles>CCCCCCCCCSCCC(N)C(=O)O</smiles>

Met or Ethionine

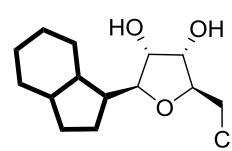

CldA analogue

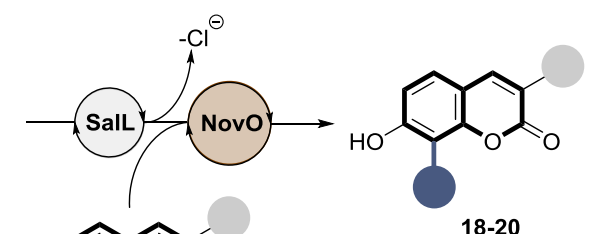<smiles></smiles>

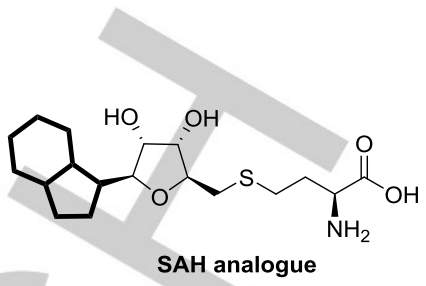

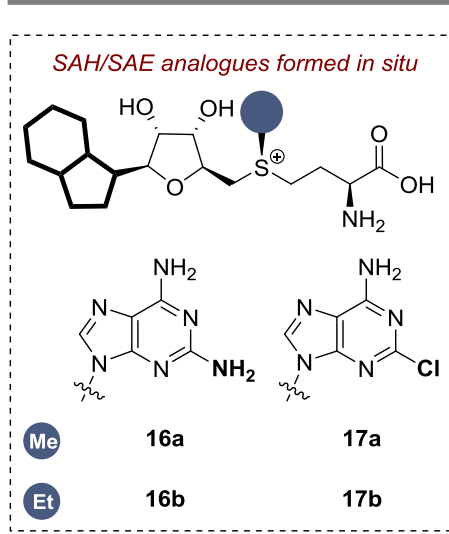

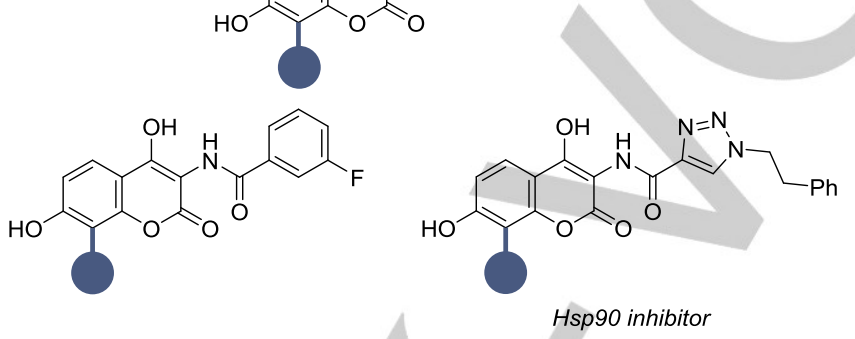

Hsp90 inhibitor

SAM $16 \quad 17$

$18 \mathrm{a}$

$18 b$

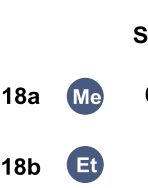

$16 \quad 17$

95100

$\begin{array}{lll}6 & 7 & 24\end{array}$

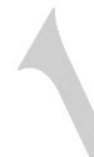

$19 \mathrm{~b}$
$15 \quad 33 \quad 95$

$\begin{array}{lll}3 & 2 & 21\end{array}$

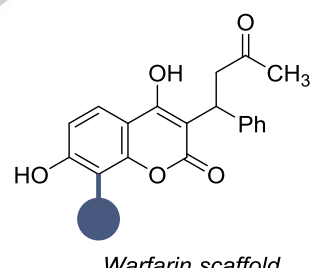

SAM $16 \quad 17$

20

20b

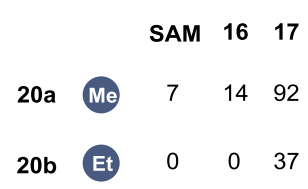

Figure 6. Representative substrate scope of tandem enzymatic (m)ethylation of coumarin substrates enhanced by nucleobase modifications on the SAM/SAE cofactor. \% conversions were determined by RP-HPLC. ${ }^{[52]}$

\section{Towards the Development of an Orthogonal Biocatalytic Alkylation Platform}

In this Concept article we have highlighted some of the exciting new developments in late-stage alkylation. ${ }^{[16-18]}$ Although comparable chemical methods in late-stage alkylation are improving, ${ }^{[58]}$ at present these currently do not rival the chemoselectivity of enzymatic processes. The recent development of cyclic cofactor regeneration cascades, alongside strategies which enhance alkyl transfer by strategic positioning of modifications, offers exciting opportunities to further enhance the scope and flexibility of late-stage alkylation by integrating these concepts. The substrate promiscuity of MAT enzymes in this respect are particularly attractive for SAM analogue synthesis which have been optimized by rational design. $\left.{ }^{21,} 25,48-49\right]$ Furthermore, since ATP is present in cells in millimolar concentrations, there exists considerable potential to engineer cascade checkpoints by directed evolution and developing latestage alkylation platforms which function in live cells or cell lysates provide additional opportunities to enhance the efficiency and flexibility of the platform. ${ }^{[59-60]}$

Our recent contribution as well as other previous work to the area has shown that strategic modification of the cofactor is also an emerging strategy to enhance (m)ethyl transfer. ${ }^{[61-62]}$ Thus, this concept could be developed further where the addition of modified 'bumps' are selective for corresponding MTase 'holes'. This 'bump and hole' approach has been applied to great effect in chemical genetics to probe particular biological functions of enzymes. ${ }^{[63]}$ However, the application of similar principles in the biocatalytic research space could be further expanded in the biocatalytic arena. If orthogonal SAM cofactor analogue-MTase pairs can be identified, then this could open up possibilities to establish parallel alkylation cascades capable of functioning in live cells or cell lysates working alongside endogenous methylation processes essential to cellular function.

\section{Acknowledgements}

We thank the Biotechnology and Biological Sciences Research Council (BBSRC) for funding a studentship for I.J.W.M (BB/ M016366/1; BB/N016378/1).

Keywords: alkylation $\bullet$ biocatalysis $\cdot S$-adenosylmethionine regeneration $\cdot$ cascade

[1] M. M. Suzuki, A. Bird, Nat. Rev. Genet. 2008, 9, 465-476.

[2] Y. Yue, J. Liu, C. He, Genes Dev. 2015, 29, 1343-1355.

[3] J. Liu, X. Dou, C. Chen, C. Chen, C. Liu, M. M. Xu, S. Zhao, B. Shen, Y. Gao, D. Han, C. He, Science 2020, 367, 580-586.

[4] K. Hyun, J. Jeon, K. Park, J. Kim, Exp. Mol. Med. 2017, 49, e324-e324

[5] J. Murn, Y. Shi, Nat. Rev. Mol. Cell Biol. 2017, 18, 517527. 
[6] E. Guccione, S. Richard, Nat. Rev. Mol. Cell Biol. 2019, 20, 642-657

[7] A. H. K. Al Temimi, M. Martin, Q. Meng, D. C. Lenstra, P. Qian, H. Guo, E. Weinhold, J. Mecinović, ChemBioChem 2020, 21, 392-400.

[8] B. J. C. Law, M. R. Bennett, M. L. Thompson, C. Levi, S. A. Shepherd, D. Leys, J. Micklefield, Angew. Chem. Int. Ed. 2016, 55, 2683-2687

[9] B. J. C. Law, A.-W. Struck, M. R. Bennett, B. Wilkinson, J. Micklefield, Chem. Sci. 2015, 6, 2885-2892.

[10] J. Zhao, D. Zhang, W. Zhang, M. A. Stashko, D.

DeRyckere, E. Vasileiadi, R. E. Parker, D. Hunter, Q. Liu Y. Zhang, J. Norris-Drouin, B. Li, D. H. Drewry, D. Kireev, D. K. Graham, H. S. Earp, S. V. Frye, X. Wang, J. Med. Chem. 2018, 61, 10242-10254.

[11] R. Angell, N. M. Aston, P. Bamborough, J. B. Buckton, S Cockerill, S. J. deBoeck, C. D. Edwards, D. S. Holmes, K. L. Jones, D. I. Laine, S. Patel, P. A. Smee, K. J. Smith, D. O. Somers, A. L. Walker, Bioorg. Med. Chem. Lett. 2008, 18, 4428-4432.

[12] C. S. Leung, S. S. F. Leung, J. Tirado-Rives, W. L. Jorgensen, J. Med. Chem. 2012, 55, 4489-4500.

[13] H. Schönherr, T. Cernak, Angew. Chem. Int. Ed. 2013, 52 , 12256-12267.

[14] Y. Chen, Chem. Eur. J. 2019, 25, 3405-3439.

[15] J. Boström, D. G. Brown, R. J. Young, G. M. Keserü, Nat. Rev. Drug Discov. 2018, 17, 709-727.

[16] J. Deen, C. Vranken, V. Leen, R. K. Neely, K. P. F. Janssen, J. Hofkens, Angew. Chem. Int. Ed. 2017, 56, 5182-5200.

[17] A.-W. Struck, M. L. Thompson, L. S. Wong, J. Micklefield, ChemBioChem 2012, 13, 2642-2655.

[18] M. R. Bennett, S. A. Shepherd, V. A. Cronin, J. Micklefield, Curr. Opin. Chem. Biol. 2017, 37, 97-106.

[19] M. Tomkuvienè, M. Mickutè, G. Vilkaitis, S. Klimašauskas, Curr. Opin. Biotech. 2019, 55, 114-123.

[20] T. D. Huber, F. Wang, S. Singh, B. R. Johnson, J. Zhang, M. Sunkara, S. G. Van Lanen, A. J. Morris, G. N. Phillips, J. S. Thorson, ACS Chem. Biol. 2016, 11, 2484-2491.

[21] S. Singh, J. Zhang, T. D. Huber, M. Sunkara, K. Hurley, R. D. Goff, G. Wang, W. Zhang, C. Liu, J. Rohr, S. G. Van Lanen, A. J. Morris, J. S. Thorson, Angew. Chem. Int. Ed. 2014, 53, 3965-3969. . Tor, Org. Biomol. Chem. 2016, 14, 6189-6192. M. Thomsen, S. B. Vogensen, J. Buchardt, M. D. Burkart, R. P. Clausen, Org. Biomol. Chem. 2013, 11, 7606-7610.

[24] J. M. Lipson, M. Thomsen, B. S. Moore, R. P. Clausen, J. J. La Clair, M. D. Burkart, ChemBioChem 2013, 14, 950 953.

[25] N. V. Cornelissen, F. Michailidou, F. Muttach, K. Rau, A. Rentmeister, Chem. Commun. 2020, 56, 2115-2118.

[26] K. Hartstock, B. S. Nilges, A. Ovcharenko, N. V. Cornelissen, N. Puellen, A. M. Lawrence-Doerner, S. A. Leidel, A. Rentmeister, Angew. Chem. Int. Ed. 2018, 57, 6342-6346.

[27] J. C. Sadler, L. D. Humphreys, R. Snajdrova, G. A. Burley, ChemBioChem 2017, 18, 992-995.

[28] J. Zhang, Y. G. Zheng, ACS Chem. Biol. 2016, 11, 583597.

[29] V. M. Richon, D. Johnston, C. J. Sneeringer, L. Jin, C. R. Majer, K. Elliston, L. F. Jerva, M. P. Scott, R. A. Copeland, Chem. Biol. Drug Des. 2011, 78, 199-210.

[30] H. Wu, C. Tian, X. Song, C. Liu, D. Yang, Z. Jiang, Green Chem. 2013, 15, 1773-1789.

[31] M. Fontecave, M. Atta, E. Mulliez, Trends Biochem. Sci. 2004, 29, 243-249.

[32] S. Mordhorst, J. Siegrist, M. Müller, M. Richter, J. N. Andexer, Angew. Chem. Int. Ed. 2017, 56, 4037-4041.

[33] D. J. Porter, J. Biol. Chem. 1993, 268, 66-73.

[34] Y. Kusakabe, M. Ishihara, T. Umeda, D. Kuroda, M Nakanishi, Y. Kitade, H. Gouda, K. T. Nakamura, N. Tanaka, Sci. Rep. 2015, 5, 16641.

[35] C. Liao, F. P. Seebeck, Nat. Catal. 2019, 2, 696-701.

[36] A. Alissandratos, Biophys. Rev. 2020, 12, 175-182.
[37] T. D. Huber, J. A. Clinger, Y. Liu, W. Xu, M. D. Miller, G. N. Phillips, J. S. Thorson, ACS Chem. Biol. 2020, 15, 695705.

[38] J. Siegrist, S. Aschwanden, S. Mordhorst, L. ThoenyMeyer, M. Richter, J. N. Andexer, ChemBioChem 2015, 16, 2576-2579.

[39] C. Sommer-Kamann, A. Fries, S. Mordhorst, J. N. Andexer, M. Mueller, Angew. Chem. Int. Ed. 2017, 56, 4033-4036.

[40] C. Liao, F. P. Seebeck, Angew. Chem. Int. Ed. 2020, 59, 7184-7187.

[41] G. Lukinavičius, V. Lapienè, Z. Staševskij, C. Dalhoff, E. Weinhold, S. Klimašauskas, J. Am. Chem. Soc. 2007, 129, 2758-2759.

[42] C. Dalhoff, G. Lukinavičius, S. Klimašauskas, E. Weinhold, Nat. Chem. Biol. 2005, 2, 31-32.

[43] W. Peters, S. Willnow, M. Duisken, H. Kleine, T. Macherey, K. E. Duncan, D. W. Litchfield, B. Lüscher, E. Weinhold, Angew. Chem. Int. Ed. 2010, 49, 5170-5173.

[44] T. D. Huber, B. R. Johnson, J. Zhang, J. S. Thorson, Curr. Opin. Biotech. 2016, 42, 189-197.

[45] H. Stecher, M. Tengg, B. J. Ueberbacher, P. Remler, H. Schwab, H. Griengl, M. Gruber-Khadjawi, Angew. Chem Int. Ed. 2009, 48, 9546-9548.

[46] V. Goyvaerts, S. Van Snick, L. D'Huys, R. Vitale, M. Helmer Lauer, S. Wang, V. Leen, W. Dehaen, J. Hofkens, Chem. Commun. 2020, 56, 3317-3320.

[47] R. S. Firestone, V. L. Schramm, J. Am. Chem. Soc. 2017, 139, 13754-13760.

[48] F. Wang, S. Singh, J. Zhang, T. D. Huber, K. E. Helmich, M. Sunkara, K. A. Hurley, R. D. Goff, C. A. Bingman, A. J. Morris, J. S. Thorson, G. N. Phillips, Jr., FEBS J. 2014, 281, 4224-4239.

[49] M. Dippe, W. Brandt, H. Rost, A. Porzel, J. Schmidt, L. A. Wessjohann, Chem. Commun. 2015, 51, 3637-3640.

[50] A. S. Eustáquio, F. Pojer, J. P. Noel, B. S. Moore, Nat. Chem. Biol. 2007, 4, 69-74.

[51] J. C. Sadler, C. H. Chung, J. E. Mosley, G. A. Burley, L. D. Humphreys, ACS Chem. Biol. 2017, 12, 374-379.

[52] I. J. W. McKean, J. C. Sadler, A. Cuetos, A. Frese, L. D. Humphreys, G. Grogan, P. A. Hoskisson, G. A. Burley, Angew. Chem. Int. Ed. 2019, 58, 17583-17588.

[53] W. L. Yeo, X. Chew, D. J. Smith, K. P. Chan, H. Sun, H. Zhao, Y. H. Lim, E. L. Ang, Chem. Commun. 2017, 53, 2559-2562.

[54] S. Thompson, Q. Zhang, M. Onega, S. McMahon, I. Fleming, S. Ashworth, J. H. Naismith, J. Passchier, D. O'Hagan, Angew. Chem. Int. Ed. 2014, 53, 8913-8918.

[55] G. Qu, A. Li, Z. Sun, C. G. Acevedo-Rocha, M. T. Reetz, Angew. Chem. Int. Ed., 0.

[56] F. H. Arnold, Angew. Chem. Int. Ed. 2018, 57, 4143-4148.

[57] C. Zeymer, D. Hilvert, Ann. Rev. Biochem. 2018, 87, 131157

[58] D. A. DiRocco, K. Dykstra, S. Krska, P. Vachal, D. V. Conway, M. Tudge, Angew. Chem. Int. Ed. 2014, 53, 4802-4806.

[59] R. A. Sheldon, D. Brady, Chem. Commun. 2018, 54, 6088-6104.

[60] J. Rolf, K. Rosenthal, S. Lütz, Catalysts 2019, 9, 190.

[61] Z. C. J. Lu, G. D. Markham, J. Biol. Chem. 2002, 277, 16624-16631.

[62] O. M. Ottink, F. H. T. Nelissen, Y. Derks, S. S. Wijmenga, H. A. Heus, Anal. Biochem. 2010, 396, 280-283.

[63] K. Islam, Cell Chem. Biol. 2018, 25, 1171-1184. 


\section{Entry for the Table of Contents}

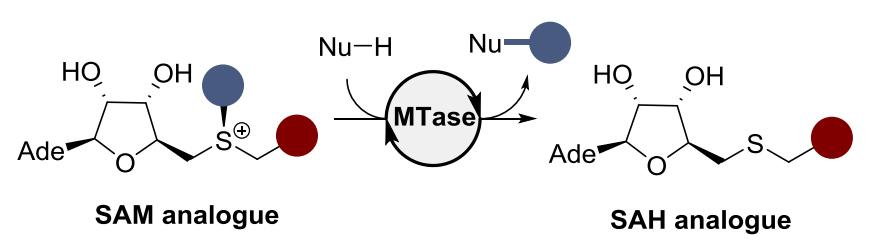

Enzymatic approaches which transfer a methyl group from $S$ adenosylmethionine to a target substrate is a powerful method used by nature to alter biological function. Enzymatic methylation is now emerging as a platform for biocatalytic alkylation of small molecules and biomacromolecules. This Concept article summarises recent approaches and challenges towards establishing a generalized platform for biocatalytic alkylation.

@BurleyResearch; @PaulHoskisson 